\title{
IR Spectroscopic Characterization of Plant Leaves, Endemic to Hot Regions, in Two Senescent States ${ }^{\dagger}$
}

\author{
Marija Strojnik ${ }^{1, *}$, Roberto C. Barragan ${ }^{2}$ and Guillermo Garcia Torales ${ }^{2}$ \\ 1 Optical Research Center, Apdo. Postal 1-948, C.P. 37000 Leon, Guanajuato, Mexico \\ 2 Department of Electronics and Computation, College of Exact Sciences and Engineering, University of \\ Guadalajara, C.P. 44100 Guadalajara, Mexico; robertobarragan.gdl@gmail.com (R.C.B.); \\ garcia.torales@academicos.udg.mx (G.G.T.) \\ * Correspondence: mstrojnik@gmail.com; Tel.: +480-294-7419 \\ + Presented at the 15th International Workshop on Advanced Infrared Technology and Applications \\ (AITA 2019), Florence, Italy, 17-19 September 2019.
}

Published: 10 October 2019

\begin{abstract}
We propose monitoring the state of the health and senescence of the oak leaves in narrow spectral intervals around $0.9 \mu \mathrm{m}, 1.8 \mu \mathrm{m}$ and $3.45 \mu \mathrm{m}$. The easiest and the most cost-effective strategy would be to implement an electro-optical remote sensing system featuring a commercial camera incorporating a traditional Si CCD detector, and a wide transmission filter, blind to the visible radiation, from about 0.82 to $0.95 \mu \mathrm{m}$.
\end{abstract}

Keywords: forests; tree canopy; remote sensing; fuel accumulation; spectral signature of oak leaves; monitoring strategies; optimal spectral range

\section{Introduction}

Within the last few years the forest fires have increasingly devastated the surface of the Earth on all continents. The preservation of forest is particularly important in dry and hot regions, where they take a long time to establish and it may be difficult to reforest there after a major devastation. Environmental scientists have proposed that increased fire occurrence is a consequence of unusual climate changes that we have been experiencing. Within the northern continents, it is believed that tropical forests must be preserved in their natural condition to provide oxygen and to clean the atmosphere for the whole Earth [1,2].

Forests are the main climate regulator in the metropolitan areas, such as the La Primavera forest just outside Guadalajara, the second most populous city in Mexico with the metropolitan population of about 5 million inhabitants. This forest area has been a devastated by a series of fires in the last decade, deteriorating the quality of life in the nearby city.

The average annual temperature in Guadalajara is $19.6^{\circ} \mathrm{C}$. In a year, the average rainfall is 941 $\mathrm{mm}$, or about $80 \mathrm{~mm}$ per month, nearly $25 \%$ more than for Germany at $700 \mathrm{~mm}$ per year. This is four times more than Arizona with about $200 \mathrm{~mm}$ per year, and 50\% more than Leon, Mexico, at $600 \mathrm{~mm}$ and about the same temperature. The Amazon region has an average rainfall of about $5500 \mathrm{~mm}$, with some regions nearly $20,000 \mathrm{~mm}$. Thus, Guadalajara is hot, but it receives enough rain for forest populated with region-adapted oak trees. Thick leathery leave cover characterizes them. With this protection, the leaves retain water well during the dry periods, preventing rapid evaporation during the heat.

In Mexico, in small areas of forestation, it is quite common that the undergrowth is cleared using annual controlled fires. This generates a lot of smoke, including water vapor, because the growth is still young and plants are often growing, carbon dioxide takes the oxygen out of the atmosphere, and 
sot that is particularly annoying when people breath in from the atmosphere. Recently, Mexico City was surrounded by fires to the point that the by-products obscured the Sun during day time, and children were excused from classes to prevent breathing problems. Before undertaking a controlled fire, it is important to know how much fuel has accumulated in lower regions of the landscape, so that fire does not expand out of control. Overall, controlled and frequently applied fires are considered part of maintaining the health of a forest region, because undergrowth interferes with large trees, and provides space where more dead leaves get to accumulate, and provide potential fuel reservoir. Needless to say, a large number of fires are started because campers do not know how to dispose of previously used fire, and by accidentally throwing away a match after lighting a cigarette. A significant number of fires happen naturally and would die off naturally, because this is a natural cycle of life and death of a tree. The fir may naturally start by lightening, either in the middle of the forest of on a high point of a mountain that has not seen rain for a while.

This was a case of the Yarnell Hill fires where a dry storm in Arizona Mountains initiated a fire, one of twelve that particular day [6]. Of all those, only the Yarnell Hill fire evolved into a huge fire. This fire was significant, first, because humans decided to live too close to the wilderness that was not protected or monitored. Second, it represents a fire where the highest number of (elite) firefighters died in the history of record-keeping in the USA. Due to the rapid spread of fires, we do not hope to be able to monitor sufficiently frequently to asses fires when they are in process, but we wish to accumulate the data of where the fuel has been accumulating to such a high degree that fire should be kept from such regions after it has started.

Finally, we are interested in monitoring the death of leaves due to senescence or presence of disease. Several tree diseases have been propagating in Mexico and devastating region after region, engulfing mercilessly tree after tree. One tree can be cured or cut down if we are aware that a disease has struck a region. A whole forest may take 15 years to reforest and grow to the point of serving as a functional air filter for a metropolis.

\section{Materials and Methods}

We are developing techniques to monitor the state of health of the Primavera forest so it can perform its function as the lungs of the City of Guadalajara and any negative trends might be detected before the damage becomes irreversible. Specific species of oaks that we study are quite common in the Primavera and with large canopy and big leaves provide generous protection against the sun. They are Quercus resinosa Liebm. [7] and Quercus magnoliifolia Née [8]. We collect information to assess the following potential scenarios using a ground-controlled drone that we equipped initially with a remotely controlled camera. It could follow a prescribed path above the forest to assess imaging through a filter that is sensitive to particular spectral regions where changes are most apparent.

We studied leaves from two endemic tree species in the Primavera forest to obtain information about their biochemical composition and physiology. The general leaf structure of dicotyledon plants is shown in Figure 1a: it includes the upper cuticle and epidermis (adaxial), palisade mesophyll, spongy mesophyll, and the lower epidermis and cuticle (abaxial) [3].

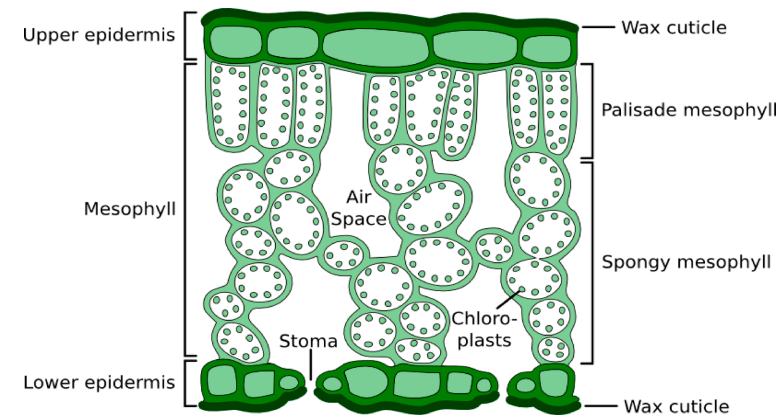

(a) Leaf structure

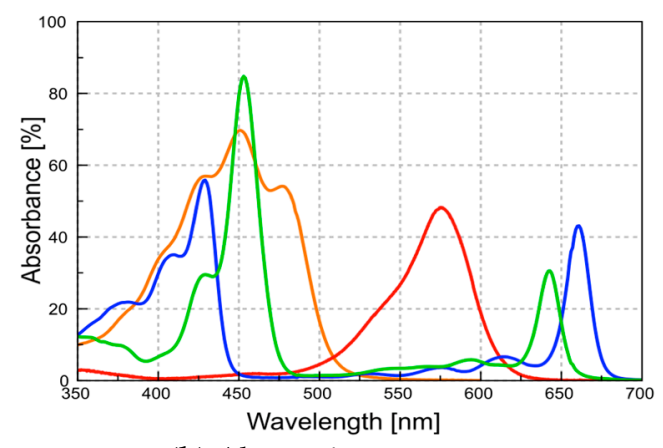

(b) Absorption spectrum 
Figure 1. (a) Leaf structure and (b) absorption spectra of its principal pigments: freshly isolated chlorophyll-a is denoted blue, chlorophyll-b is green, $\beta$-carotene is orange, and anthocyanin with $\mathrm{pH}$ 1.0 is marked as red (after [3] and [4]).

We measure the reflectance of fresh and dry samples with a Vis-NIR spectrometer that uses a calibrated light source. We furthermore study the diffuse reflectance spectra of the leaves of several species for two senescent states. The first spectral interval encompasses from $0.4 \mu \mathrm{m}$ to $2.5 \mu \mathrm{m}$, which corresponds to the solar radiation, and the second one from $2.5 \mu \mathrm{m}$ to $20 \mu \mathrm{m}$.

\section{Results}

The pigments determine the color of the plant and provide important information about plant physiological status, illustrated in Figure $1 \mathrm{~b}$. They are generally found in chloroplast that contains chlorophyll, carotenoids, and anthocyanins. The main plant pigment is chlorophyll a, chlorine that absorbs blue and red bands featuring reflectivity of green wavelengths, giving terrestrial plants and algae their green color.

The chlorophyll $\mathrm{b}$ is an accessory pigment, used to absorb the electromagnetic radiation to stimulate photosynthesis. The chlorophyll content can directly determine the plant status. It gives an indirect estimation of the nutrient levels because it stores nitrogen, and its content is related to plant stress and senescence [3]. Anthocyanins are present in all tissues of higher plants, including leaves. Its production is induced under stress condition or infection by pathogens.

The carotenoids are needed for photosynthetic function inside the vegetable cell. Spectral reflectances in Vis-NIR range of (a) Quercus resinosa Liebm. and (b) Quercus magnoliifolia Née are presented in Figure 2. Green line denotes the spectrum of a fresh leaf (green upon visual inspection), and the red one corresponds to the senescent leaf (brown upon visual inspection). Within the visible range, the reflectance of the fresh leave peaks in green, while that of a senescent leave is flat and increasing. Both leaves have quite similar behavior. Figure 3 features the Fourier transform FT-IR reflectance spectrum of (a) Quercus resinosa Liebm. and (b) Quercus magnoliifolia Née from 1.4-20 $\mu \mathrm{m}$ for a fresh and a senescent leaf. The general features of both leaves are similar and they change in the same manner upon aging.

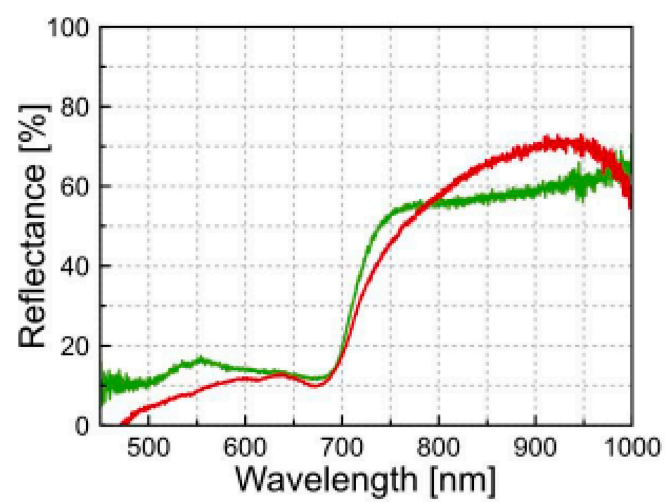

(a) Quercus resinosa Liebm.

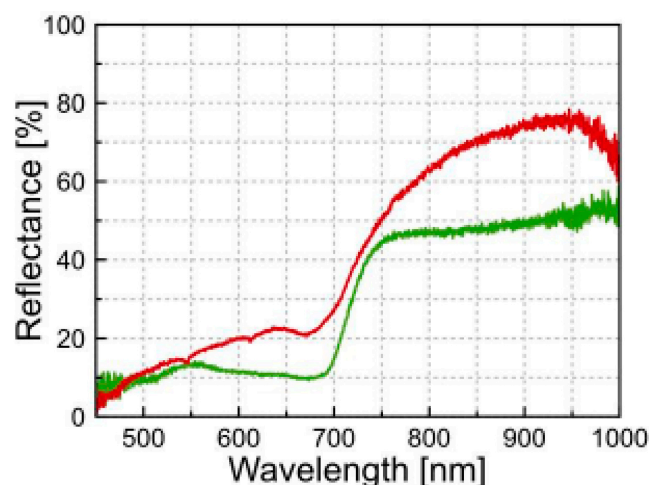

(b) Quercus magnoliifolia Née

Figure 2. Measured spectral reflectance in Vis-NIR range of (a) Quercus resinosa Liebm.and (b) Quercus magnoliifolia Née (after [5]). Green line is the spectrum of a fresh leaf (green upon visual inspection), and red corresponds to the senescent leaf (brown upon visual inspection). 


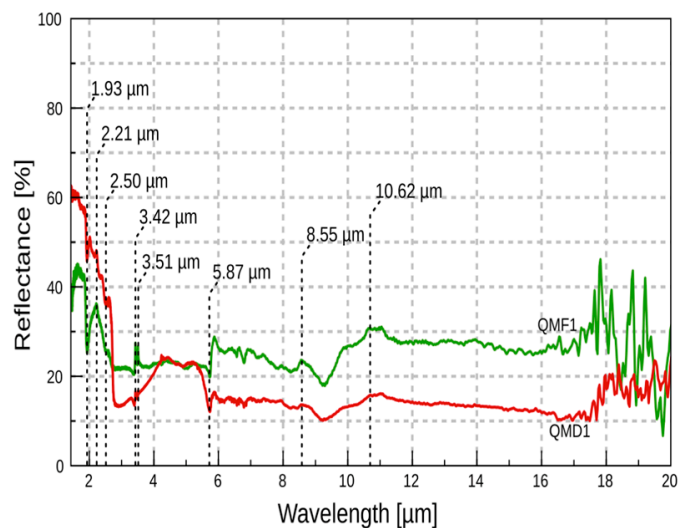

(a) Quercus resinosa liebm.

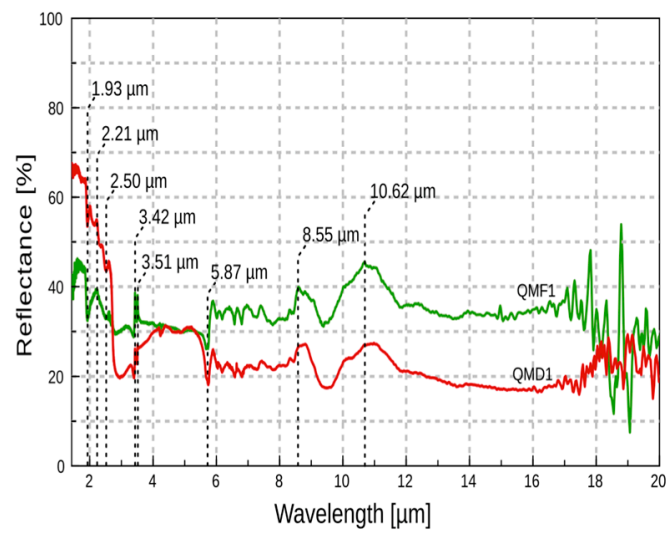

(b) Quercus magnolifolia nee

Figure 3. Fourier transform FT-IR reflectance spectrum of (a) Quercus resinosa Liebm. and (b) Quercus magnoliifolia Née from 1.4-20 $\mu \mathrm{m}$ (after [9]). Green line denotes the spectrum of a fresh leaf (green, upon visual inspection), and the red one corresponds to the senescent leaf (brown, upon visual inspection).

\section{Discussion}

The study identifies the changes in the specific signatures of the leaves concerning the internal decomposition of the foliar plate, due to dehydration of the leaf, the loss of chlorophyll, the production of anthocyanin, and the destruction of the cellular structure. As water absorption in IR is nearly constant, we observe after $5.5 \mu \mathrm{m}$ a nearly constant decrease in reflectance by about $12 \%$. In the spectral range between about $4 \mu \mathrm{m}$ and $5.5 \mu \mathrm{m}$ there is no significant change in reflectance. There is an appreciable difference in signals between 1.5 and $4 \mu \mathrm{m}$, with the reflectance of an old leave first much higher and then much lower than that of the fresh one, with a crossover point at $3.8 \mu \mathrm{m}$.

\section{Conclusions and Further Work}

The results of this study lead us to propose monitoring the state of the health and senescence of the leaves in narrow spectral intervals around $0.9 \mu \mathrm{m}, 1.8 \mu \mathrm{m}$ and $3.45 \mu \mathrm{m}$. The easiest and the most cost-effective strategy would be to implement an electro-optical remote sensing system, mounted on a drone and controlled from the ground. It would feature a commercially available camera incorporating a traditional Si CCD detector, and a $0.2-\mu \mathrm{m}$ wide transmission filter. Such filters, blind to the visible radiation, are commercially available (see, for example, Thorlabs, a transmissive filter with a cut-on wavelength at about 0.80 microns). The long wavelength cutoff is accomplished due to trailing off of the Si-detector sensitivity at around $1 \mu \mathrm{m}$.

\section{References}

1. 2019 Amazon Rainforest Wildfires. Available online: https://en.wikipedia.org/wiki/2019_Amazon_ rainforest_wildfires (accessed on 10 September 2019).

2. World Forest Fires. Available online: https://fires.globalforestwatch.org/home/ (accessed on 10 September 2019).

3. Boanares, D.; Ferreira, B.; Kozovits, A.; Sousa, H.; Isaias, R.; França, M. Pectin and cellulose cell wall composition enables different strategies to leaf water uptake in plants from tropical fog mountain. Plant Physiol. Biochem. 2018, 122, 57-64.

4. $\quad$ Gates, D.M.; Keegan, H.J.; Schleter, J.C.; Weidner, V.R. Spectral properties of plants. Appl. Opt. 1965, 4, 1120.

5. Garcia-Torales, G.; Rivas, A.R.; Contreras, F.J.G.; Campos, R.C.B. Optical spectral characterization of leaves for endemic species from La Primavera forest. In Proceedings of the Infrared Remote Sensing and Instrumentation XXV, San Diego, CA, USA, 7 September 2017; Volume 34.

6. Strojnik, M.; Scholl, M.K. Analysis of propagation of complex fire: Case of the Yarnell Hill Fire 1. In Proceedings of the Infrared Remote Sensing and Instrumentation XXIII, San Diego, CA, USA, 1 September 2015; Volume 9608. 
7. Quercus Resinosa. Available online: http://oaks.of.the.world.free.fr/quercus_resinosa.htm (accessed on 10 September 2019.

8. Quercus Magnoliifolia. Available online: http://oaks.of.the.world.free.fr/quercus_magnoliaefolia.htm (accessed on 10 September 2019).

9. Barragán, R.C.; Strojnik, M.; Rodríguez-Rivas, A.; Torales, G.G.; González, F.J. Optical spectral characterization of leaves for Quercus Resinosa and Magnolifolia species in two senescent states. In Proceedings of the Infrared Remote Sensing and Instrumentation XXVI, San Diego, CA, USA, 18 September 2018; Volume 10765, doi:10.1117/12.2321710.

(C) 2019 by the authors. Licensee MDPI, Basel, Switzerland. This article is an open access article distributed under the terms and conditions of the Creative Commons Attribution (CC BY) license (http://creativecommons.org/licenses/by/4.0/). 